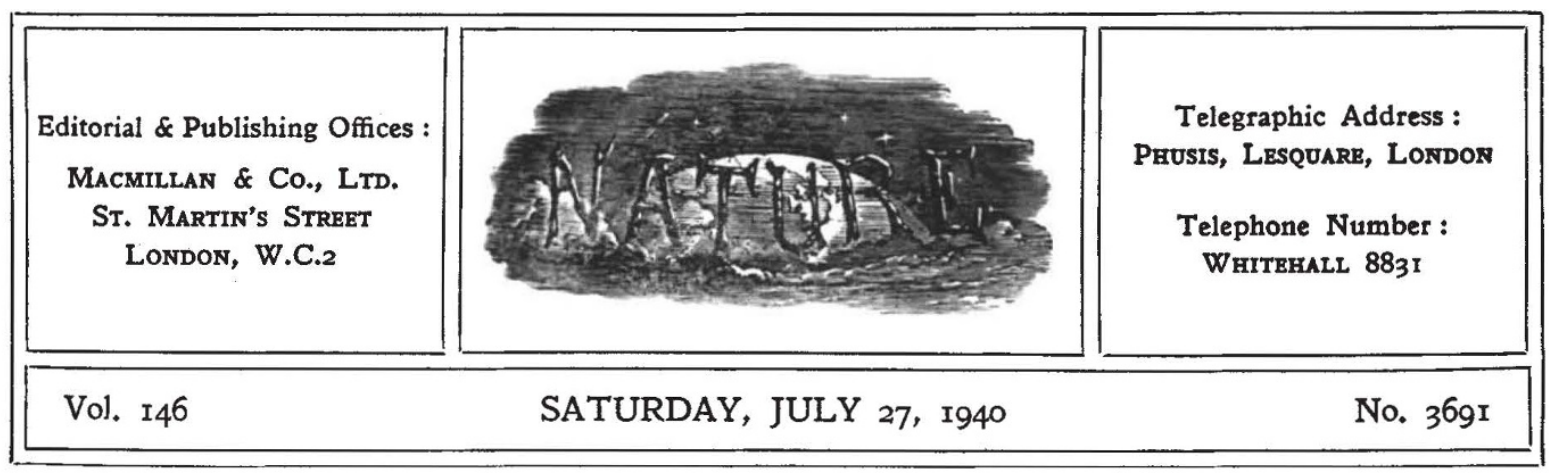

\title{
MEN OF SCIENCE AND THE WAR
}

SINCE the War, and in the months preceding it, it has been repeatedly urged in these columns that the times demand the maximum use of science and the full recognition by men of science of their social responsibilities. A year before the unstable international situation resolved itself into the present disastrous conflict, pages of NATURE were devoted to statements by the scientific leaders of the country about the urgent need for scientific workers to undertake these responsibilities, but little of practical import has resulted so far. If the War succeeds in arousing certain men of science to a realization of the social implications of their work, then it may be said that some good has come out of it, and it is to be hoped that such will be lasting. Men of science are proving invaluable at the present time; may their value still be recognized when the time for reconstruction comes.

With the War, the country implicitly assumed a reorganization so profound that the full realization of its meaning only dawned in most minds after the disasters of Norway, Flanders and France, and with the victorious onrush of the German war-machine. To-day no persuasion is needed to impress on people the necessity for making all possible use of the country's powers and resources. That message rings in our ears daily. But no efforts, however heroic, however widespread, and however energetic, will succeed in their objects without right direction-and such direction demands the full use of science.

The Germans have demonstrated that this is a mechanized and technical war. It is not sufficient therefore for us to have limitless material resources ; it is essential to use them in a thoroughly planned and integrated way. Until now (and this is still the case), planning has been the task of our political and industrial leaders and of the Civil Service alone. There is no need for us to dwell on the results of their efforts. As men of science our responsibility to-day is to see that things get done, not to blame others if they have not been done.

The important part that men of science have already played in this War has been amply recognized in these columns. The Scientific and Research Departments of the Services, the Department of Scientific and Industrial Research and its kindred bodies, and the Medical Research Council, fortified as they have been by the addition of many academic men of science, have been fulfilling their appointed duties. But many scientific workers have not been used at all, and others, who have for long been in Government service, or who have been recruited since the War, are not being used to their fullest capacities. The fundamental reason for this (and this is the fundamental defect of the whole organization) is that the functions of science have been generally conceived, to a large extent even by men of science themselves, in altogether too restricted a way. A general scientific point of view is foreign to the direction of the country, and in particular to its administrators. If this defect is to be remedied, men of science themselves must show the way.

On p. 112 of this issue is reviewed a book which deals with this very problem. One of its lessons is that in order to discover what are the urgent problems before us, and to determine their order of importance, it is first necessary to survey the whole field of national resources and national effort. This object will not be successfully achieved by administrative methods alone, and such 
methods so far constitute the only treatment of this particular question. They can lead no further than to a statement of the most apparent facts, whereas there is little doubt that a scientific approach would often reveal key problems, the solutions of which would advance matters more rapidly, and with less effort than any amount of energy directed along traditional paths. But if we are to achieve the best from a scientific approach to a fundamental survey of the problems before us, it is essential that the man of science should be given effective authority to make comprehensive inquiries, to formulate and to solve problems and, not less, to see that the solutions which he suggests are embodied in practical measures.

The above-mentioned book provides several examples where this approach has already been used successfully (for example, in dealing with the magnetic mine and with war diseases), and it indicates several others where it could be applied with all promise of success (for example, in dealing with the menace of tanks and providing an adequate food supply from domestic sources). It is apparent that the book refers, partly for reasons of space and partly because of the limitations imposed by the need for secrecy, to only a few of the many problems which could be tackled more vigorously than they seem to be at present; and the issues discussed are mainly detailed ones. More general problems are only hinted at, for clearly without the proper general fundamental survey no one is in a position to state them explicitly.
Since May, the circumstances for making full use of science have grown more favourable than ever before in the history of Great Britain. Complacency has given way to an acute appreciation of the fact that we have urgent unfulfilled needs, and failure has shown the inadequacy of traditional methods. Blame has very rightly been laid on administrators and industrial leaders for failing to achieve the desired results; but for us the lesson is rather in the failure of men of science to realize both the power that lies in their hands and their responsibility for using it. Men of science can no longer be complacent about neglect, or content with such notice as merely seeks their advice about particular issues. With few exceptions they have not regarded it as their duty to force on an unscientific administration their reading of the dangers and of the means for counteracting them. They have regarded their functions as served when their advice has been sought and given. It was not for them to see that it was acted upon. As "J. S. H." points out on p. 113, "half the battle in science consists in asking new questions which the non-scientist cannot be expected to think of".

More than this is demanded to-day. "Go to it," in the words of the new Government slogan, applies not only to the factory worker carrying out bis routine duties. It applies even more to the scientific worker-demanding of him initiative, organizing ability and drive, and the clear realization that only with the help of these can the forces of reaction and inertia be turned aside, and our war effort rapidly brought to a successful end.

\section{HOURS OF WORK AND EFFICIENCY}

D URING the nineteenth century, industrial development was governed by the claims of machinery rather than of man. It was a period of gradually increasing control of the environment through machines; at the same time, the studies made in the natural sciences and the growing knowledge of the mechanism of the body all tended to focus interest on man's likeness to a machine. Being like is not, however, equivalent to being nothing but.

The phrase "the human machine", which rightly interpreted refers to part of man's structure, besame by implication rather than by design synonymous with man himself. The idea is very old, but the actual form of the expression dates from the eighteenth century when La Mettrie published "L'Homme Machine"; he also wrote "L'Homme Plante", but nobody seems to have been interested in man as a plant.

The almost incredible result of this point of view is reflected in the treatment of industrial workers at the beginning of the nineteenth century, when even children worked in the mills for nineteen hours a day. One might indeed argue that human beings were considered inferior to machines, since care was taken to keep the latter fit. 